\title{
Visual Response Properties in the Dorsal Lateral Geniculate Nucleus of Mice Lacking the $\beta 2$ Subunit of the Nicotinic Acetylcholine Receptor
}

\author{
Matthew S. Grubb and Ian D. Thompson \\ University Laboratory of Physiology, Oxford OX1 3PT, United Kingdom
}

\begin{abstract}
We present a quantitative description of single-cell visual response properties in the dorsal lateral geniculate nucleus (dLGN) of anesthetized adult mice lacking the $\beta 2$ subunit of the nicotinic acetylcholine receptor $(\beta 2-/-)$ and compare these response properties with data from wild-type animals. Some response features, including all spatial receptive field characteristics and bursting behavior, are entirely normal in $\beta 2-1-\mathrm{dLGN}$ cells. In other respects, the responses of $\beta 2-1-\mathrm{dLGN}$ cells are quantitatively abnormal: the mutation is associated with higher spontaneous and visually evoked firing rates, faster visual response latencies, a preference for higher temporal frequencies, and a trend toward greater contrast sensitivity. The normal response properties in the $\beta 2-/-\mathrm{dLGN}$ show that none of the many effects of the mutation, including disrupted geniculate functional organization and abnormal cholinergic transmission, have any effect on spatial response characteristics and bursting behavior in $\mathrm{dLGN}$ neurons. The abnormal response characteristics in the $\beta 2-1-$ dLGN are most interesting in that they are no worse than normal; any visual processing deficits found in studies of the $\beta 2-/-$ visual cortex must therefore arise solely from abnormalities in cortical processing.
\end{abstract}

Key words: nicotinic acetylcholine receptor; dLGN; mouse; physiology; development; thalamus

\section{Introduction}

Do the functional properties of individual neurons depend on the way in which they are organized within a neural structure? One might expect so, if functional properties are shaped in any way by patterned connections between neurons. In the dorsal lateral geniculate nucleus (dLGN), most single-cell response properties are determined by feedforward input from the retina, but some, including the strength of receptive field (RF) surround mechanisms, are shaped by local thalamic circuitry (Hubel and Wiesel, 1961; Norton et al., 1989; Usrey et al., 1999). What happens to neuronal responses in the dLGN when the patterning of inputs and the local functional organization is disrupted? In mice lacking the $\beta 2$ subunit of the nicotinic acetylcholine receptor (nAChR), retinal ganglion cells in the first postnatal week lack correlated waves of spontaneous calcium-driven activity (Bansal et al., 2000) and, although they fire spikes at normal rates, display abnormal patterns of spontaneous firing (McLaughlin et al., 2003). This deficit is associated with an abnormal functional organization of the adult dLGN with respect to ocularity (Rossi et al., 2001; Muir-Robinson et al., 2002), retinotopy (Grubb et al., 2003; McLaughlin et al., 2003), and On-Off cell groupings

Received April 22, 2004; revised July 22, 2004; accepted July 22, 2004.

This work was supported by a Wellcome Trust Integrative Animal and Human Physiology program grant. M.S.G. was a student in The Wellcome Trust 4 year Neuroscience PhD program. We thank Prof. Jean-Pierre Changeux and Dr. Francesco Mattia Rossi for providing the $\beta 2-/-$ mice and Prof. Colin Blakemore for providing temporary laboratory space.

Correspondence should be addressed to Dr. lan Thompson, University Laboratory of Physiology, Parks Road, 0xford 0X13PT, UK. E-mail: ian.thompson@physiol.ox.ac.uk.

DOl:10.1523/JNEUROSCI.1527-04.2004

Copyright $\odot 2004$ Society for Neuroscience $\quad$ 0270-6474/04/248459-11\$15.00/0
(Grubb et al., 2003). Thus, both the patterning of inputs and also intrinsic neighbor relationships have been altered within the $\beta 2-/-\mathrm{dLGN}$. Is this reflected in the visual response characteristics of individual dLGN cells? If responses rely on convergent connections, this would seem a likely possibility. However, if, despite altered patterns of activity early in development, individual dLGN cells in the adult continue to be dominated by input from a single retinal ganglion cell as in normal animals (Chen and Regehr, 2000; Tavazoie and Reid, 2000), then visual responses may be unaffected. The present study aims to determine whether abnormal functional organization in the dLGN is associated with any effects on the response properties of individual neurons within the nucleus.

Of course, alterations in visual response characteristics in the $\beta 2-1-$ dLGN need not directly reflect its altered functional organization. The alterations could be retinal in origin or they could also result directly from changes in cholinergic modulation of visual responses. Acetylcholine (ACh) is known to affect the response properties of dLGN neurons: it can increase spontaneous and visually evoked firing, augment RF surround strength, and increase RF center size (Fjeld et al., 2002). By studying these response properties and others in the $\beta 2-/-\mathrm{dLGN}$, a better understanding might be gained of the role of thalamic $\beta 2$ containing $\mathrm{nAChRs}$ ( $\beta 2$-nAChRs) in such ACh-induced changes. Finally, studying the spatial response characteristics of $\beta 2-1-$ dLGN cells should identify the locus of effect of a previously reported visual deficit in the mutant. Not only do $\beta 2-/-$ mice have abnormal functional organization in the dLGN (Grubb et al., 2003; McLaughlin et al., 2003), but evoked poten- 
tial studies also reveal an abnormally low spatial acuity in the visual cortex, whereas acuity in the retina is normal (Rossi et al., $2001)$. By assessing the spatial response properties of cells in the $\beta 2-/-\mathrm{dLGN}$, this study aims to show whether spatial acuity in the $\beta 2-/-$ brain is lost in the dLGN, in the cortex, or in both.

\section{Materials and Methods}

Animals. Wild-type (WT) animals were adult ( $>3$ months of age) pigmented C57BL/6J mice of either sex weighing 20-36 gm (Harlan Olac, Oxon, UK). Responses recorded in 33 WT mice formed the data presented in a previous study (Grubb and Thompson, 2003). Along with supplementary spontaneous activity from cells recorded in an additional eight adult male WT mice, these data are used as controls in the present analyses. Mice lacking the $\beta 2$ subunit of the $\mathrm{nAChR}(\beta 2-/-)$ were generated at the Institut Pasteur (Paris, France) (Picciotto et al., 1995), and were backcrossed for at least 12 generations onto the C57BL/6J strain. Responses recorded in 17 adult male $\beta 2-/-$ mice (29-36 gm) are analyzed here. Animals were housed under a $12 \mathrm{hr}$ light/dark cycle. All procedures were conducted under the auspices of the United Kingdom Home Office project and personal licenses held by the authors.

Physiological recording. Electrophysiological recordings were performed as described previously (Grubb and Thompson, 2003; Grubb et al., 2003). Briefly, mice were initially anesthetized with 25\% Hypnorm (Janssen Animal Health, Bucks, UK) and 25\% Hypnovel (Roche Products, Herts, UK) in water for injections $(2.7 \mu \mathrm{l} / \mathrm{gm}$, i.p.) while a tracheotomy was performed and a small plastic tube was inserted. Mice were placed in a stereotaxic apparatus before the tracheal tube was connected to a respiratory pump (MiniVent 845; Hugo Sachs Elektronik, MarchHugstetten, Germany), which supplied a 1:3 mixture of oxygen and nitrous oxide along with $1-1.5 \%$ halothane for maintained anesthesia. Expired $\mathrm{CO}_{2}$ was monitored (Capstar- $100 \mathrm{CO}_{2}$ analyzer; CWE, Ardmore, PA) and maintained at $2.5-4 \%$, heart rate was monitored with an electrocardiogram $(\sim 5 \mathrm{~Hz}$ was normal), and body temperature, measured with a rectal probe, was maintained at $\sim 37^{\circ} \mathrm{C}$ by combining high ambient temperature with heat from a thermostatically coupled blanket (NP 50-7061-R; Harvard Apparatus, Kent, UK). Optics were also monitored continuously for any signs of lens opacity (Fraunfelder and Burns, 1970). Animals were not paralyzed, but eye movements are neither large nor frequent in this preparation (Grubb and Thompson, 2003) and do not differ between WT and $\beta 2-/-$ mice (Grubb et al., 2003). After a small unilateral craniotomy and durotomy, a tungsten-in-glass recording electrode (Alan Ainsworth, Northants, UK) was lowered vertically into the brain and advanced until it was within the dLGN. Signals were then filtered and thresholded to isolate the responses of single neurons. The timing of spike events was linked to the timing of visual stimulus changes using in-house software written by Darragh Smyth.

Stimulus presentation. Visually responsive neurons were first identified using a hand-held ophthalmoscope. For quantitative visual response characterization, stimuli were then presented on a cathode ray tube monitor controlled by a VSG 2/4 graphics card (Cambridge Research Systems, Rochester, UK). The display comprised $800 \times 600$ pixels and at viewing distances between 135 and $400 \mathrm{~mm}$ subtended $53-111 \times 41-95^{\circ}$; a range of distances was necessary to ensure multiple cycles when a cell responded to very low spatial frequencies (SFs). With maximum and minimum luminances of 99 and $2 \mathrm{~cd} / \mathrm{m}^{2}$ [the mean luminance for gratings was $50 \mathrm{~cd} / \mathrm{m}^{2}$, which is similar to the $25 \mathrm{~cd} / \mathrm{m}^{2}$ used by Rossi et al., (2001)], the display was the main source of illumination in an otherwise dim room. The display was initially placed with the presumptive RF a given cell at its center; mapping with reverse correlation (Grubb and Thompson, 2003; Grubb et al., 2003) then confirmed this location or directed movement of the monitor in order that the display covered the entire RF area. Only cells with RFs that could be localized in this way were subjected to subsequent analysis of response characteristics. The RF mapping procedure also identified cells as either Oncenter or Off-center (Grubb and Thompson 2003) and included extended presentations (10 sec each) of a blank screen at a mean luminance from which spontaneous activity levels were calculated.

To obtain measures of visual response characteristics, sinusoidal monochromatic vertical gratings were presented covering the full extent of the display. These gratings were drifting in all experiments, except the null test, in which they were stationary and sinusoidally contrast modulated. In all experiments, all grating parameters were kept constant, except the one under study; gratings varying in this parameter were presented in a pseudorandom sequence. Each presentation of a grating stimulus in a given repeat occurred for seven cycles; of these, only responses from the last five cycles were used to discard any flash responses to the initial presentation of the stimulus. The exception was assessing temporal frequency (TF) tuning: in these experiments, to ensure capture of enough responses to high TF stimuli, stimuli $>1 \mathrm{~Hz}$ were presented for $7 \mathrm{sec}$, with the first $2 \mathrm{sec}$ being discarded to allow for flash responses.

Histology. Recording sites were localized as described previously (Grubb and Thompson, 2003; Grubb et al., 2003). Briefly, experiments ended with a terminal injection of Sagatal $(0.3 \mathrm{ml}, 60 \mathrm{mg} / \mathrm{ml}$; RhôneMérieux, Essex, UK); mice were then perfused transcardially with PBS, followed by paraformaldehyde ( $4 \%$ in $0.1 \mathrm{~m}$ phosphate buffer; TAAB Laboratories, Berks, UK). Brains were removed, sunk in 30\% sucrose, sectioned coronally at $30-50 \mu \mathrm{m}$ on a freezing microtome, and mounted onto gelatinized slides. Staining with cresyl violet allowed the identification of small ( $6 \mu \mathrm{A}$ for $6 \mathrm{sec}$ ) electrolytic lesions made at precise locations on successful electrode penetrations. Lesion locations were then used to reconstruct electrode tracks and localize recorded neurons. Only cells unequivocally situated within the dLGN were included in the present analyses.

Fourier analysis. Responses to gratings were analyzed by first binning all responses to a given stimulus according to their poststimulus time. One hundred twenty-eight bins were used per stimulus cycle, producing a poststimulus time histogram (PSTH) for each stimulus. A Fast Fourier Transform of these data then converted these PSTH data into amplitudes (in spikes per second) and phases (in degrees or radians) of harmonics of the modulation frequency of the stimulus (Hochstein and Shapley, 1976).

A linearity index was calculated for responses to stationary, counterphased sinusoidal gratings presented at various spatial phases of the RF of a cell and at various SFs [the modified null test (Enroth-Cugell and Robson, 1966; Hochstein and Shapley, 1976)]. The mean second harmonic (F2) response amplitude across all spatial phases at a given SF was divided by the maximum fundamental (F1) response amplitude across all spatial phases at that SF, and the maximum resultant value across all SFs was taken for each cell. Cells with a linearity value $<1$ are considered linear, whereas those with values $>1$ can be classified as nonlinear (Hochstein and Shapley, 1976).

A rectification index was calculated for responses to each grating stimulus as follows:

$$
\text { rectification }=\frac{\sum_{n=2}^{n=5} A_{n} / 4}{A_{1}} \text {, }
$$

where $A_{\mathrm{n}}$ is the response amplitude at the $n$th stimulus harmonic. This index is highest $(\sim 1)$ when the average amplitude of harmonics $2-5$ $(\mathrm{F} 2-5)$ is equal to the fundamental (F1) response amplitude and lowest $(\sim 0)$ when the F1 response is completely dominant.

Curve fitting. All curve fits were performed using a least squares minimalization algorithm (Grubb and Thompson, 2003). Plots of stimulus SF versus cell F1 response amplitude were fitted with a modified difference of Gaussians (DoG) curve (Rodieck, 1965; So and Shapley, 1981; Grubb and Thompson, 2003):

$$
R(v)=b+\left(k_{\mathrm{c}}-b\right) \times\left(e^{-\left(\pi \times r_{\mathrm{c}} \times 1\right) 2}-k_{\mathrm{s}} \times e^{\left.-\pi \times r_{s} \times 1\right) 2}\right),
$$

where $R$ is the $\mathrm{F} 1$ response amplitude, $v$ is the SF, $b$ is the baseline response, $k_{\mathrm{c}}$ is the area under the Gaussian function of the RF center, $k_{\mathrm{s}}$ is the relative area under the Gaussian function of the RF surround, and $r_{\mathrm{c}}$ and $r_{\mathrm{s}}$ are the radii of the center and surround Gaussian functions, respectively, at the point each mechanism has reached 1/e of its peak. This DoG fit enabled measurements of the SF optimum of a given cell (or "peak") and cutoff (taken as the high SF at which F1 response amplitude drops to $1 \%$ of its maximum value). 
Plots of stimulus TF versus cell F1 response amplitude were fitted with an atheoretical function comprising two half-Gaussians (Grubb and Thompson, 2003):

$$
\begin{aligned}
& R(\omega)=b_{1}+\left(a-b_{1}\right) \times e^{-((p-\omega) / s) 2} \text { for } \omega<p, \\
& R(\omega)=b_{2}+\left(a-b_{1}\right) \times e^{-((p-\omega) / s) 2} \text { for } \omega>p,
\end{aligned}
$$

where $R$ is the $\mathrm{F} 1$ response amplitude, $\omega$ is the TF, $p$ is the peak TF, $a$ is the response amplitude at optimum TF, $s$ is the Gaussian spread, $b_{1}$ is the baseline on the low-frequency side of the curve, and $b_{2}$ is the baseline on the high-frequency side of the curve. The fit enabled measurement of a "high 50 " value: the high TF at which F1 response amplitude drops to 50\% of its maximum. Plots of stimulus TF versus cell F1 response phase were simply fitted with a straight line. The slope of this line was taken as a measure of the response latency of a cell (Hawken et al., 1996; Grubb and Thompson, 2003).

Plots of stimulus Michelson contrast versus cell F1 response amplitude were fitted using a hyperbolic function (Albrecht and Hamilton, 1982; Grubb and Thompson, 2003) of the form, as follows:

$$
R(c)=b+\left(R_{\max }-b\right) \times \frac{c^{n}}{c^{n}+h^{n}}
$$

where $R$ is the $\mathrm{F} 1$ response amplitude, $c$ is contrast, $R_{\max }$ is the maximum response, $h$ is the contrast at which $R$ reaches half of $R_{\max }$, and $n$ is the rate of change. The fit was used to generate two contrast response measures: "gain," the slope of a tangent to the hyperbolic function at $20 \%$ of its height at $100 \%$ contrast, and " $c_{50}$ " the contrast at which the function reaches $50 \%$ of its value at $100 \%$ contrast (Grubb and Thompson, 2003).

Identification of burst responses. Spikes forming part of bursts triggered by low-threshold calcium spikes (LTS bursts) were identified from temporal patterns in the firing of dLGN cells. From intracellular recordings in the cat dLGN, Lu et al. (1992) observed that LTS bursts were typically preceded by $\geq 100 \mathrm{msec}$ of silence and consisted of spikes that occurred within $4 \mathrm{msec}$ of each other. These authors showed that $>98 \%$ of "bursts" identified using these criteria were attributable to LTS activity. Given that LTS activity and burst firing appear rather conserved across different mammalian species (Jahnsen and Llinas, 1984; McCormick and Feeser, 1990; Zhan et al., 1999; Ramcharan et al., 2000), including mice (Kim et al., 2001), the same criteria were used to identify burst firing in the responses of mouse dLGN neurons here. Specifically, the first action potential in a burst had a preceding silent period of $\geq 100 \mathrm{msec}$ and a following interspike interval (ISI) of $\leq 4 \mathrm{msec}$. Any subsequent spikes with preceding ISIs of $\leq 4 \mathrm{msec}$ were designated as additional action potentials in a burst. These criteria picked out stereotypical patterns of spike firing and identified burst firing with the same properties as those previously recorded in vitro in other mammals. In particular, burst length depended on the duration of the initial within-burst ISI (McCarley et al., 1983; Radhakrishnan et al., 1999), and intraburst ISIs gradually increased in duration (McCarley et al., 1983; Radhakrishnan et al., 1999; Reinagel et al., 1999) (data not shown).

Statistical analysis. Normality in statistical samples was assessed using a Kolmogorov-Smirnov test. Those samples deemed normal were described using the mean \pm SEM and were compared using parametric tests. Those deemed non-normal were described using the median and were compared using nonparametric tests. To allow ANOVA, some nonnormal samples underwent logarithmic transformation to render them normally distributed. All comparison tests were two-tailed, with the level of significance set at 0.05 .

\section{Results}

Previous extracellular recordings of visually driven activity in $\beta 2-/-\mathrm{dLGN}$ neurons revealed their visual response characteristics to be qualitatively normal. Objective mapping with reverse correlation showed that cells in the $\beta 2-/-\mathrm{dLGN}$, like their WT counterparts (Grubb and Thompson, 2003), possess RFs that are dominated by an approximately circular "center" mechanism responsive to either increases (On-center) or decreases (Off-
A
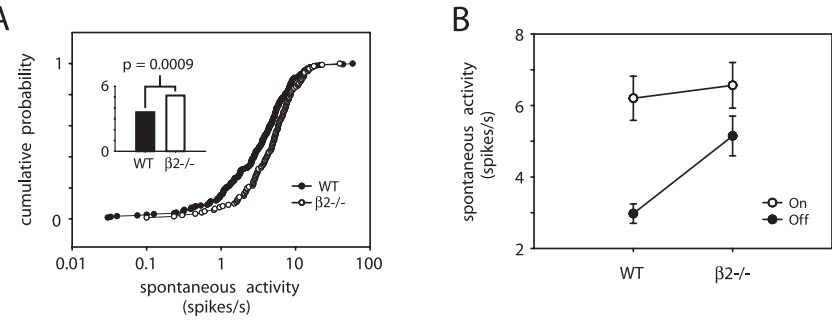

Figure 1. Spontaneous activity is higher in the $\beta 2-/-\mathrm{dLGN}$. $A$, A cumulative probability plot reveals a marked difference in spontaneous activity levels between the two samples: $\beta 2-/-$ neurons tend to fire more spontaneous spikes. Note the logarithmic $x$-axis. Inset, The bar plot confirms that the medians of the two distributions are significantly different (WT, 3.6 spikes/sec; $\beta 2-/-, 5.14$ spikes/sec; Mann-Whitney $U$ test; $p=0.0009)$. $B$, Mean spontaneous firing levels in 0n-center and Off-center cells in the WT and $\beta 2-/-\mathrm{dLGN}$. Spontaneous activity is higher in the $\beta 2-1-\mathrm{dLGN}$ and in 0 -center cells, although the largest difference between the two genotypes occurs in Off-center spontaneous firing. The error bars show SEM.

center) in stimulus luminance (Grubb et al., 2003). Previous recordings also demonstrated that both WT and $\beta 2-/-\mathrm{dLGN}$ cells are always monocularly driven (Grubb et al., 2003). The present study extends this previous work by asking whether visual processing in $\beta 2-/-\mathrm{dLGN}$ is quantitatively normal. We use a range of tests to compare the response characteristics of cells in the $\beta 2-/-\mathrm{dLGN}$ with the previously described (Grubb and Thompson, 2003) response properties of cells in the WT dLGN.

\section{Spontaneous activity is higher in $\beta 2-/-\mathrm{dLGN}$ cells}

Over all cells, the firing rate of $\beta 2-/-\mathrm{dLGN}$ cells to a blank gray screen was significantly higher than that of WT dLGN neurons (median: WT: 3.6 spikes/sec, $n=220 ; \beta 2-/-: 5.1$ spikes $/ \mathrm{sec}, n=$ 121; Mann-Whitney $U$ test; $p=0.0009$ ) (Fig. $1 A$ ). Because spontaneous activity is significantly different in On-center versus Offcenter cells in the WT dLGN (Grubb and Thompson, 2003), an ANOVA analysis was used to assess both genotypic and RF center-type differences across WT and $\beta 2-/-\mathrm{dLGN}$ neurons. To allow this analysis, firing rates were logarithmically transformed to render them normally distributed as assessed with a Kolmogorov-Smirnov test. Significant effects were found for genotype $\left(F_{(1,336)}=13.59 ; p<0.001\right)$, RF center type $\left(F_{(1,336)}=\right.$ $14.41 ; p<0.001)$, and for the genotype $\times$ RF center-type interaction $\left(F_{(1,336)}=7.98 ; p=0.005\right)$. These effects revealed that spontaneous activity is higher in $\beta 2-/-$ than in WT dLGN cells, that spontaneous firing is higher in On-center versus Off-center cells, and that the difference between On-center and Off-center spontaneous activity is much less marked in the $\beta 2-/-\mathrm{dLGN}$ than in the WT nucleus (Fig. $1 B$ ). Indeed, the difference between $\beta 2-/-$ and WT spontaneous firing rates seems mostly attributable to increased activity in $\beta 2-/$ - Off-center cells.

\section{Like WT neurons, almost all $\beta 2-/-$ dLGN cells sum spatial inputs in a linear manner}

Linearity of spatial summation was assessed by means of a modified null test (Enroth-Cugell and Robson, 1966; Hochstein and Shapley, 1976; Grubb and Thompson, 2003). Cells were presented with stationary sinusoidal gratings, the contrast of which was modulated sinusoidally. Gratings were presented at a number of different spatial phases and had SFs at, or at integer multiples of, the optimum SF of each cell. In the $\beta 2-/-$ dLGN, 29 cells were tested at their preferred SF; 22 of these cells were also tested at twice the optimum SF, and 14 cells were also tested at three times the optimum SF. The WT sample consisted of 34 null-tested neurons: all were tested at their optimum SF, 18 at twice the opti- 
mum, and 5 at three times the optimum (Grubb and Thompson, 2003). Stimulus TF was either $1 \mathrm{~Hz}$ or optimal; the maximum stimulus contrast was $70 \%$. In a linear neuron, it should be possible to find two spatial phases at which the introduction of a contrast-modulated grating does not produce any alteration in firing rate. These "null" positions occur when On and Off influences are perfectly balanced across all RF domains (Enroth-Cugell and Robson, 1966). In 28 of 29 (97\%) $\beta 2-/-$ dLGN cells, we found evidence for null positions at all tested SFs. Like WT dLGN neurons, which all possessed null positions at all tested SFs (Grubb and Thompson, 2003), almost all cells in the $\beta 2-/-$ dLGN therefore appeared to sum spatial inputs across their RFs in a linear manner.

An extension to the null test states that, in linear cells, responses should be dominated by the fundamental (F1) harmonic component (Hochstein and Shapley, 1976). In addition, F1 response amplitude should vary sinusoidally with systematic changes in stimulus phase (Hochstein and Shapley, 1976). Precisely, this behavior is illustrated in WT $(A, B)$ and $\beta 2-/-(D, E)$ dLGN example cells in Figure 2. In these plots, by convention, F1 response amplitudes are represented as negative when their phase differs by $90-270^{\circ}$ from the phase of the maximum F1 response. Null positions are then revealed by zerocrossings of the $\mathrm{F} 1$ response amplitude function. In both the WT and $\beta 2-/-$ samples, almost all cells showed evidence of linear spatial summation: F1 response components were dominant, varied sinusoidally with the phase of counterphased gratings, and crossed the zero line twice at null positions. These response properties are precisely those shown by X-cells in the carnivore dLGN (Hochstein and Shapley, 1976). There was some evidence of nonlinear behavior, however. As discussed previously (Grubb and Thompson, 2003), the WT sample contained two cells (of 34) in which, at a single SF, F2 response components were dominant and varied sinusoidally with stimulus phase (Fig. $2 C$ ). Such nonlinear responses are reminiscent of geniculate neurons with On-Off RFs (Lennie and Perry, 1981). The $\beta 2-/-$ sample, in contrast, contained one cell (of 29) that displayed summation nonlinearities like those seen in carnivore Y-cells (Hochstein and Shapley, 1976). At low SFs, the F1 responses of this cell were dominant, and null positions were present, but at higher SFs, responses were dominated by an F2 component that did not vary with the phase of counterphased gratings (Fig. $2 F$ ). Both the WT and $\beta 2-/-$ dLGN samples therefore contain a very low proportion of neurons that sum inputs nonlinearly across their RFs.

Linearity of spatial summation can be quantified using an index based on F1 and F2 response amplitudes to counterphased gratings of varying spatial phase (Hochstein and Shapley, 1976) (see Materials and Methods). Index values $<1$ denote linear spatial summation, whereas values $>1$ are indicative of summation nonlinearities. Distributions of linearity values across the WT and $\beta 2-1-$ samples are shown in Figure 3 and are extremely $35^{\text {th }}$ percentile
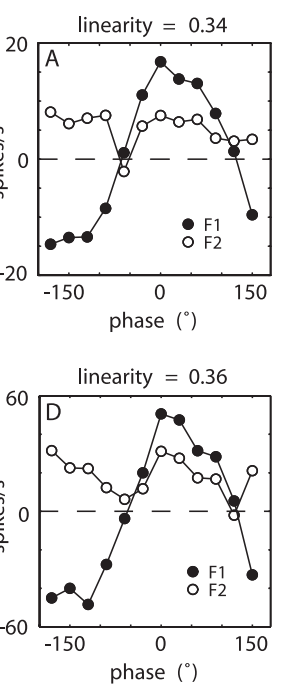

$70^{\text {th }}$ percentile
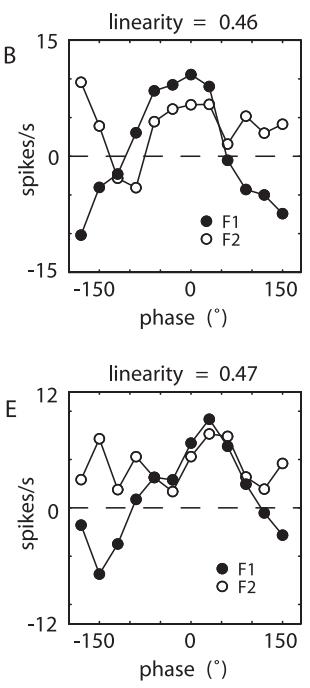

non-linear
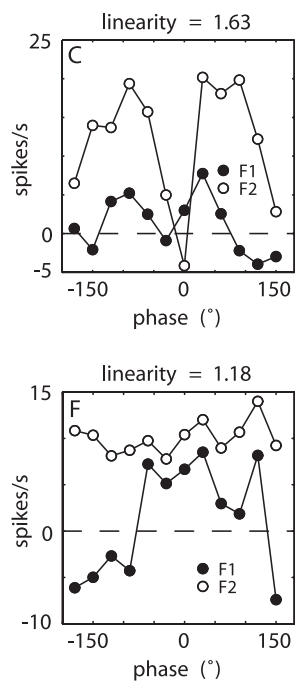

Figure 2. Examples of modified null tests of spatial summation in three WT and three $\beta 2-/-\mathrm{dLGN}$ cells. Cells were presented with stationary sinusoidal gratings of various spatial phases, the contrast of which was counterphased sinusoidally. (F) fundamental (F1) and second (F2) stimulus harmonics were used to calculate an index of linearity of spatia 列

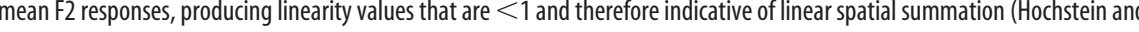
列

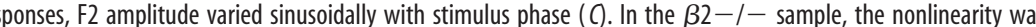
but did not vary sinusoidally with stimulus phase $(F)$.

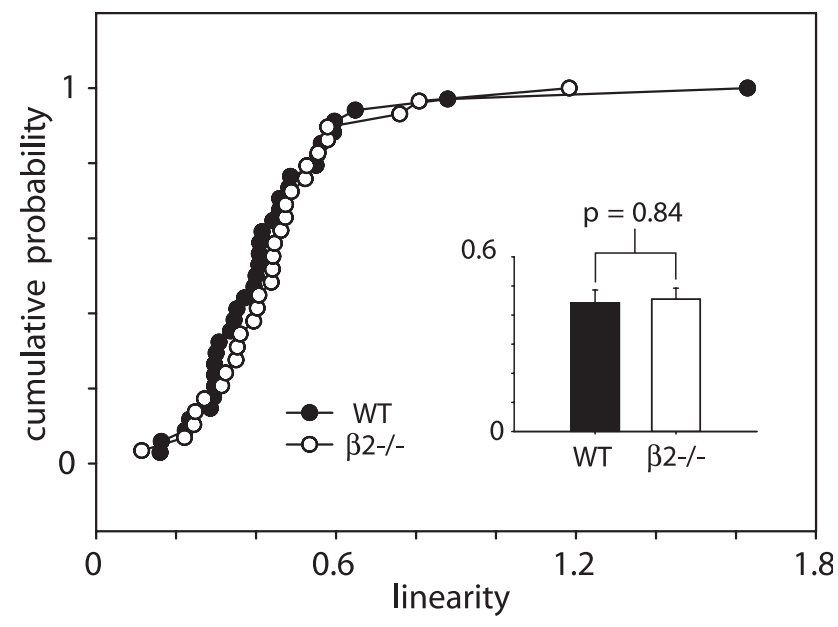

Figure 3. There was no difference in spatial summation between WT and $\beta 2-/-\mathrm{dLGN}$ cell samples. The main cumulative probability plot shows very little difference in the distributions of linearity values in the two samples, whereas the bar plot (inset) shows that the means of the two groups are not significantly different (mean \pm SEM: WT, $0.44 \pm 0.04 ; \beta 2-/-$, $0.45 \pm 0.04 ; t$ test; $p=0.84$ ). The error bars show SEM.

similar. Both samples contain only a single cell with a linearity value $>1$ and possess mean linearity values that are not significantly different (mean \pm SEM: WT, $0.44 \pm 0.04 ; \beta 2-/-, 0.45 \pm$ $0.04 ; t$ test; $p=0.84$ ) (Fig. 3 ). Linearity values were also not significantly different between On-center and Off-center $\beta 2-/-$ 
$50^{\text {th }}$ percentile

$75^{\text {th }}$ percentile
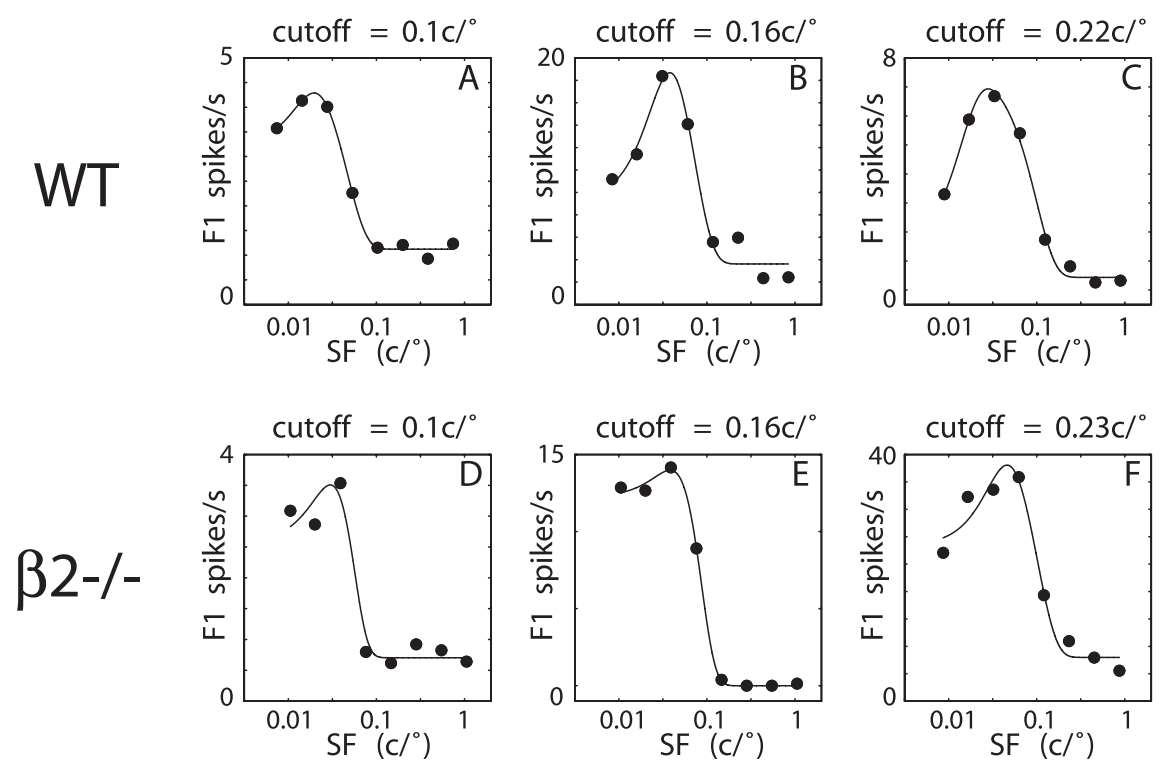

Figure 4. Examples of SF tuning in three WT and three $\beta 2-/-d L G N$ cells. The circles show F1 response amplitudes to drifting sinusoidal gratings of varying SF (TF, $1 \mathrm{~Hz}$; contrast, $70 \%$ ); the lines show the best-fitting DoG curve to these data. Neurons were ranked according to their SF cutoff (see Results), and plots for cells at the 25th, 50th, and 75th percentiles are shown. In both WT and $\beta 2-/-$ mice, cells responded best to very low SFs. SF tuning in both samples was extremely similar: most WT and $\beta 2-/-$ neurons were like those presented in being bandpass tuned for $S F$, and the similarity in cutoff values for cells at similar percentiles in the two samples is striking. Spatial tuning parameters for all example cells: $A: k_{c}, 5.28 ; k_{s}, 0.50 ; r_{c}, 6.79^{\circ} ; r_{s}, 22.15^{\circ} ;$ peak, 0.02 $c /^{\circ}$; cutoff, $0.10 \mathrm{c} /^{\circ} ; B: k_{c}, 28.25 ; k_{s}, 0.79 ; r_{c}, 4.49^{\circ} ; r_{s}, 11.78^{\circ} ;$ peak, $0.038 \mathrm{c} /^{\circ} ;$ cutoff, $0.16 \mathrm{c} /^{\circ} ; c: k_{c}, 7.63 ; k_{s}, 0.87 ; r_{c}, 3.22^{\circ} ; r_{s}$, $22.12^{\circ}$; peak, $0.028 \mathrm{c} /^{\circ}$; cutoff, $0.22 \mathrm{c} /^{\circ} ; D: k_{c}, 40.78 ; k_{s}, 0.95 ; r_{c}, 8.3^{\circ} ; r_{s}, 8.89^{\circ} ;$ peak, $0.03 \mathrm{c} /^{\circ} ;$ cutoff, $0.1 \mathrm{c} /^{\circ} ; E: k_{c}, 52.19 ; k_{s}, 0.77$; $r_{c}, 4.87^{\circ} ; r_{s}, 6.16^{\circ} ;$ peak, $0.038 \mathrm{c} /^{\circ} ;$ cutoff, $0.16 \mathrm{c} /{ }^{\circ} ; F: k_{c}, 51.43 ; k_{s}, 0.58 ; r_{c}, 3.14^{\circ} ; r_{s}, 9.45^{\circ} ;$ peak, $0.046 \mathrm{c}^{\circ} ;$ cutoff, $0.23 \mathrm{c} /^{\circ}$. $25^{\text {th }}$ percentile

in this analysis reveals a significant effect of RF center type [more spontaneously active On-center cells have less rectified responses $\left.\left(F_{(1,152)}=6.7 ; p=0.01\right)\right]$ but no significant effects of genotype $\left(F_{(1,152)}=\right.$ $0.8 ; p=0.38)$ or genotype $\times \mathrm{RF}$ center type $\left(F_{(1,152)}=0.1 ; p=0.74\right)$. Similar levels of rectification in WT and $\beta 2-/-$ dLGN cells might seem surprising given the differences in spontaneous activity between the genotypes. However, the correlation between spontaneous activity and rectification is weak and depends on a range of values from 0 to $>50$ spikes/sec, whereas the difference in spontaneous activity between WT and $\beta 2-/-$ is only 1.5 spikes/sec. WT$\beta 2-/-$ differences in measures that depend on F1 response amplitude cannot be attributable to differences in rectification between the two groups.

\section{Spatial RF properties do not differ between WT and $\beta 2-/-$ neurons}

To quantitatively assess the spatial RF features of $\beta 2-/-$ dLGN cells, we first constructed SF tuning curves. As well as directly revealing important aspects of the spatial processing capabilities of cells, responses of linear cells to gratings of varying SF can be used to predict their RF structure, and vice versa. We presented drifting sinusoidal gratings of varying SF (TF, $1 \mathrm{~Hz}$; cells (mean \pm SEM: On-center, $0.43 \pm 0.06$; Off-center, $0.49 \pm$ 0.03 ; $t$ test with Welch correction for unequal variances; $p=$ $0.38)$, and an ANOVA analysis found no effects on linearity of genotype $\left(F_{(1,59)}=0.12 ; p=0.73\right)$, RF center type $\left(F_{(1,59)}=0.05\right.$; $p=0.83)$, or genotype $\times \operatorname{RF}$ center type $\left(F_{(1,59)}=1.7 ; p=0.2\right)$. Like the WT dLGN, the $\beta 2-/-$ dLGN is almost entirely populated by On-center and Off-center cells that sum spatial inputs in an equally linear manner across their RFs.

As well as being extremely similar in terms of linearity of spatial summation, WT and $\beta 2-/-$ dLGN cells are also indistinguishable in terms of a separate type of response linearity: rectification. Rectification describes how far the response of a cell to a sinusoidal stimulus deviates from a sinusoidal pattern of increases and decreases in the firing rate. It can be measured by taking into account the relative amplitudes of F1 versus higher (F2, F3, etc.) components of responses to a given stimulus: as the responses of a cell become more rectified, F1 response amplitude and higher harmonic response amplitudes become more equal (see Materials and Methods). Less spontaneously active cells are often more rectified: because the firing rate cannot ever drop below zero, decreases in the spike rate in cells with low spontaneous activity levels cannot follow sinusoidal changes in stimulus parameters. Indeed, in responses to drifting sinusoidal gratings (SF, optimal; TF, $1 \mathrm{~Hz}$; contrast, 70\%), spontaneous firing rates correlate negatively with rectification values (see Materials and Methods) in WT (Spearman $r=-0.25 ; p=0.02 ; n=92$ ) and $\beta 2-/-$ (Spearman $r=-0.34 ; p=0.007 ; n=64$ ) neurons. However, these correlations are rather weak, and direct comparison shows that rectification medians in WT and $\beta 2-/-\mathrm{dLGN}$ samples do not differ significantly (median: WT, $0.31 ; \beta 2-/-$, $0.28 ; p=0.43$ ). Taking possible On-Off differences into account contrast, 70\%) and measured F1 firing rates in response to these stimuli. The resultant tuning curves were then fitted with a DoG equation (Rodieck, 1965; So and Shapley, 1981) (see Materials and Methods) that models the center and surround RF mechanisms of a cell as symmetrical antagonistic Gaussian functions. Successful fits provided measures of the strengths and sizes of the center and surround RF regions of a cell. Because they provided a smooth fit to raw data, these fits also allowed the calculation of two important SF tuning parameters: peak and cutoff (see Materials and Methods).

SF tuning curves were well fitted with DoG functions in 64 $\beta 2-/-$ dLGN cells. The WT sample comprised 92 such cells (Grubb and Thompson, 2003). Most $\beta 2-/-$ cells possessed moderately bandpass SF tuning curves, with steadily decreasing response amplitude either side of a clear SF peak (Fig. 4). A minority of cells, however, possessed low-pass SF tuning, in which progressively lower SFs were never met with a decrease in response amplitude. The proportion of low-pass $\beta 2-/-$ cells was not different from that observed in the WT sample [WT, 12 of 92 (13\%); $\beta 2-/-, 7$ of 64 (11\%); Fisher's exact test; $p=0.81$.

The example SF tuning curves in Figure 4 suggest that the spatial response properties of $\beta 2-/-\mathrm{dLGN}$ cells might not be very different from those of WT dLGN cells: when ranked in terms of SF cutoff, values for cells at the same percentiles in the two samples are extremely similar. Indeed, of all the RF parameters assessed using SF tuning curves, only the strength of the RF center, $k_{\mathrm{c}}$, differed between WT and $\beta 2-/-$ cells: it was significantly higher in the $\beta 2-/-$ dLGN (median: WT, $14.9 ; \beta 2-/-$ : 24.5; Mann-Whitney $U$ test; $p=0.0003$ ) (Fig. $5 A_{1}$ ). Because the center radius, $r_{\mathrm{c}}$, did not differ between the two groups (mean \pm SEM: WT, $5.6 \pm 0.4^{\circ} ; \beta 2-/-, 5.4 \pm 0.4^{\circ} ; t$ test with Welch 
$A_{1}$

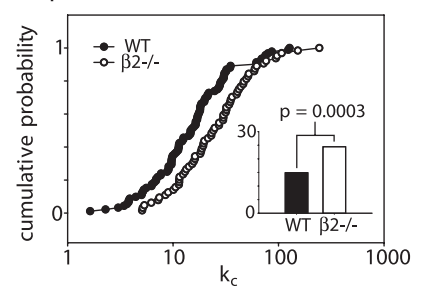

B

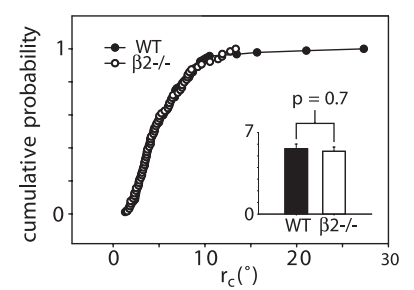

$\mathrm{D}$

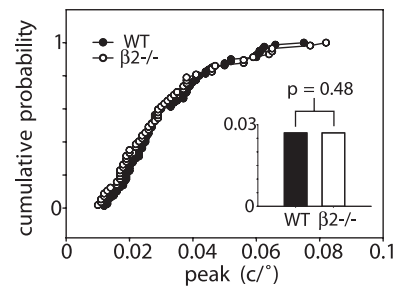

2

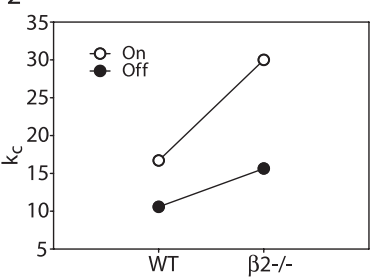

C

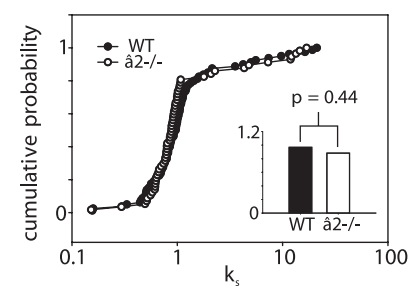

$\mathrm{E}$

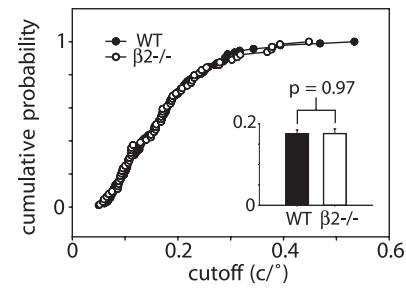

Figure 5. Comparison of SF tuning in the WT and $\beta 2-/-\mathrm{dLGN} . A$, RF center strength, $k_{\mathrm{c}}$, is higher in $\beta 2-1-\mathrm{dLGN}$ cells. The cumulative probability plot (1) shows that $k_{c}$ values across the $\beta 2-I-$ sample tend to be larger than those in the WT sample (note the logarithmic $x$-axis), whereas the bar plot (inset) shows that the medians of these two samples are significantly different (median: WT, 14.9; $\beta 2-/-, 24.5$; Mann-Whitney U test; $p=0.0003$ ). Plot 2 shows that median $k_{c}$ is higher in both 0 -center and Off-center cells in the $\beta 2-/-\mathrm{dLGN}$, but more so in 0 -center cells. $B$, The RF center radius, $r_{c}$, does not differ between WT and $\beta 2-1-$ $\mathrm{dLGN}$ cells. The distributions of values in the two samples are almost identical (note the logarithmic $x$-axis), and the means of these samples are not significantly different (mean \pm SEM: WT, $5.6 \pm 0.4^{\circ} ; \beta 2-1-, 5.4 \pm 0.4^{\circ} ; t$ test; $\left.p=0.7\right)$. The error bars show SEM. $C, k_{s}, \mathrm{RF}$ surround strength, is no different in WT and $\beta 2-/-\mathrm{dLGN}$ cells. Distributions of values in the two samples are extremely similar. The bar plot (inset) shows that the medians of the two samples do not differ significantly (median: WT, $0.97 ; \beta 2-/-, 0.88$; Mann-Whitney $U$ test; $p=0.44) . D$, Peak SF is not different in the WT and $\beta 2-/-\mathrm{dLGN}$. The distributions of values in the two samples overlap considerably, and their medians are not significantly different (median: WT, $0.027 \mathrm{C}^{\circ} ; \beta 2-/-, 0.027 \mathrm{C} /{ }^{\circ}$; Mann-Whitney $U$ test; $\left.p=0.48\right)$. E, The WT and $\beta 2-/-d L G N$ do not differ in terms of spatial acuity. Distributions of SF cutoff values are almost identical in the two groups, and the means of these samples are not significantly different (mean \pm SEM:WT, $0.18 \pm 0.009 \mathrm{C} /{ }^{\circ} ; \beta 2-/-, 0.18 \pm 0.01 \mathrm{c} /{ }^{\circ} ; t$ test,$p=0.97$ ). The error bars show SEM.

correction; $p=0.7$ ) (Fig. 5B), the larger $k_{\mathrm{c}}$ in $\beta 2-/-$ cells shows that their RF center mechanism is simply more responsive than that of WT neurons. In other words, $\beta 2-/-$ cells fire more spikes than WT cells to appropriate stimuli presented in the center of their RF, but the spatial extent of that center region does not differ between the two groups. The RF surround mechanism of $\beta 2-/-$ neurons is also the same size as, but more responsive than, that of WT neurons. Although the example cells in Figure 4 may suggest that RF surrounds are weaker in $\beta 2-/-$ neurons (the roll-off in response amplitude at low SFs is less pronounced in cells $E$ and $F$ than in cells $B$ and $C$ ), this is simply a consequence of drawing example cells from a sample ranked in terms of cutoff values: surround radius, $r_{\mathrm{s}}$, and $k_{\mathrm{s}}$, a measure of the balance between center and surround mechanisms, did not differ between WT and $\beta 2-/-$ dLGN neurons (median $r_{\mathrm{s}}$ : WT, $17^{\circ} ; \beta 2-/-, 17.4^{\circ}$; Mann-Whitney $U$ test; $p=0.97$; median $k_{s}:$ WT, $0.97 ; \beta 2-1-$, 0.89; Mann-Whitney $U$ test; $p=0.44$ ) (Fig. $5 C$ ). As well as firing

more spontaneous spikes (Fig. 1), cells in the $\beta 2-/-$ dLGN are therefore more responsive to visual stimuli than their WT counterparts. However, spatial RF features and SF tuning parameters are not affected by the $\beta 2-1-$ mutation. Peak SF (median: WT, 0.027 cycles $(\mathrm{c}) /{ }^{\circ} ; \beta 2-/-, 0.027 \mathrm{c} /{ }^{\circ}$; Mann-Whitney $U$ test; $p=$ 0.48 ) (Fig. $5 D$ ) and SF cutoff (mean \pm SEM: WT, $0.18 \pm 0.009$ $c /{ }^{\circ} ; \beta 2-l-, 0.18 \pm 0.01 \mathrm{c} /{ }^{\circ} ; t$ test; $\left.p=0.97\right)($ Fig. $5 E$ ) were no different between WT and $\beta 2-/-$ dLGN cells.

Is the WT- $\beta 2-/-$ difference in $k_{c}$, like the difference in spontaneous activity described above, mainly attributable to increased firing rates in $\beta 2-/-$ Off-center neurons? Inspection of median $k_{\mathrm{c}}$ values for On-center and Off-center cells in the two genotypes (Fig. $5 A_{2}$ ) suggests not: the difference between WT and $\beta 2-/-$ cells is largest in On-center neurons. In addition, an ANOVA analysis on logarithmically transformed $k_{\mathrm{c}}$ values found effects of genotype $\left(F_{(1,140)}=33.3 ; p<0.0001\right)$ and RF center type (Oncenter cells have higher $\left.k_{c} ; F_{(1,140)}=18.6 ; p<0.0001\right)$ but no effect of the genotype $\times$ RF center-type interaction $\left(F_{(1,140)}=\right.$ 2.9; $p=0.09$ ). Similar On-Off analyses for other SF tuning measures found no significant effects of genotype, RF center type, or the genotype $\times \mathrm{RF}$ center-type interaction $(p>0.05)$. The $\beta 2-I-$ mutation thus affects visually evoked firing rates and does not affect spatial RF properties, equally across On-center and Off-center dLGN cells.

\section{WT- $\boldsymbol{\beta 2}-/-$ differences in temporal response properties}

We assessed the temporal features of visual responses in the $\beta 2-/-\mathrm{dLGN}$ by presenting drifting sinusoidal gratings of various TFs (SF, optimal; contrast, 70\%). F1 response amplitudes were recorded, and the resultant TF tuning curves were fitted with an atheoretical function (see Materials and Methods), which allowed the calculation of two temporal response parameters: optimal TF, or "TF peak," and high ${ }_{50}$, the high TF at which response amplitude drops to half its maximum height.

TF tuning curves were successfully fitted with two halfGaussian functions (see Materials and Methods) in $42 \beta 2-1-$ dLGN cells responding to gratings. The WT sample contained 47 such tuning curves (Grubb and Thompson, 2003). All fitted $\beta 2-/-$ neurons, like their WT counterparts (Fig. $6 A_{1-3}$ ), showed bandpass TF tuning (Fig. $6 A_{4-6}$ ), with decreases in response amplitude often more rapid above than below peak TF (Fig. $6 A_{5,6}$ ). The example tuning curves displayed in Figure $6 \mathrm{~A}$ suggest that $\beta 2-/-$ dLGN cells outperform their WT counterparts temporally: $\beta 2-/-$ neurons prefer higher TFs than WT cells at similar sample percentiles. Indeed, mean TF peak and high ${ }_{50}$ values were both significantly higher in the $\beta 2-1-$ sample (TF peak, mean \pm SEM: WT, $3.9 \pm 0.2 \mathrm{~Hz} ; \beta 2-/-, 4.9 \pm 0.3 \mathrm{~Hz}$; test; $p=0.02$ ) $\left(\right.$ Fig. $\left.7 A_{1}\right)\left(\right.$ high $_{50}$, mean \pm SEM: WT, $7.3 \pm 0.4 \mathrm{~Hz} ; \beta 2-/-$, $9.2 \pm 0.4 \mathrm{~Hz} ; t$ test; $p=0.001)\left(\right.$ Fig. $\left.7 B_{1}\right)$.

$\beta 2-/-$ cells also respond to visual stimuli more quickly than WT neurons. Visual response latency can be measured from responses to gratings of different TFs by plotting stimulus TF against the phase of each $\mathrm{F} 1$ response component (Fig. $6 \mathrm{~B}$ ). The slope of the best-fitting straight line to these data then gives a measure of response latency (Hawken et al., 1996; Grubb and Thompson, 2003). The example plots in Figure $6 B$ show that response latency varies rather little across both WT and $\beta 2-/-$ samples; nevertheless, $\beta 2-I-$ cells tend to have faster latencies than WT cells at similar sample percentiles. Indeed, median latency was significantly smaller in the $\beta 2-/-$ sample (median: WT, 92 msec; $\beta 2-/-, 84$ msec; Mann-Whitney $U$ test; $p=$ 0.002) (Fig. 7 $C_{1}$ ).

$\beta 2-/-$ TF properties did resemble their WT counterparts, 
A

WT
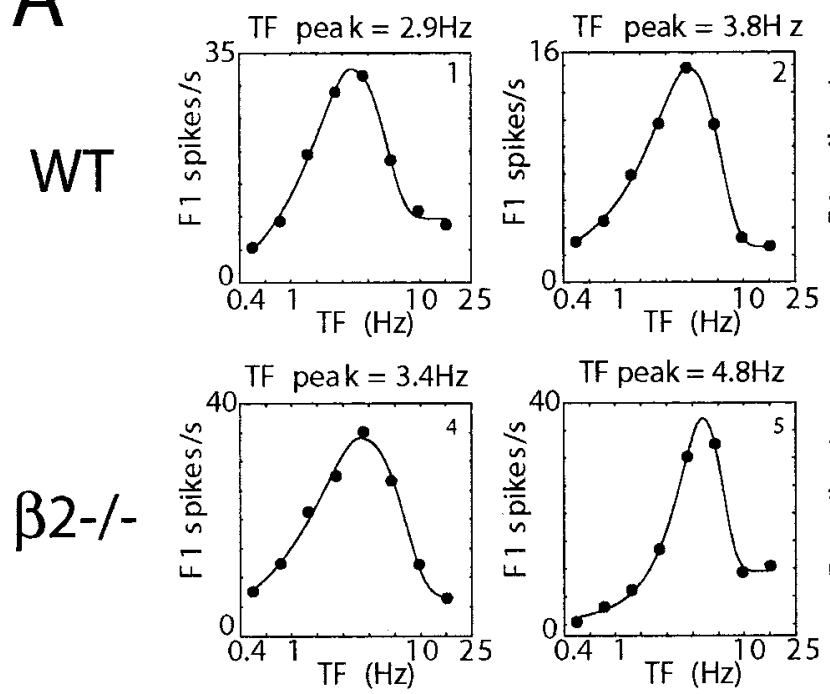

B
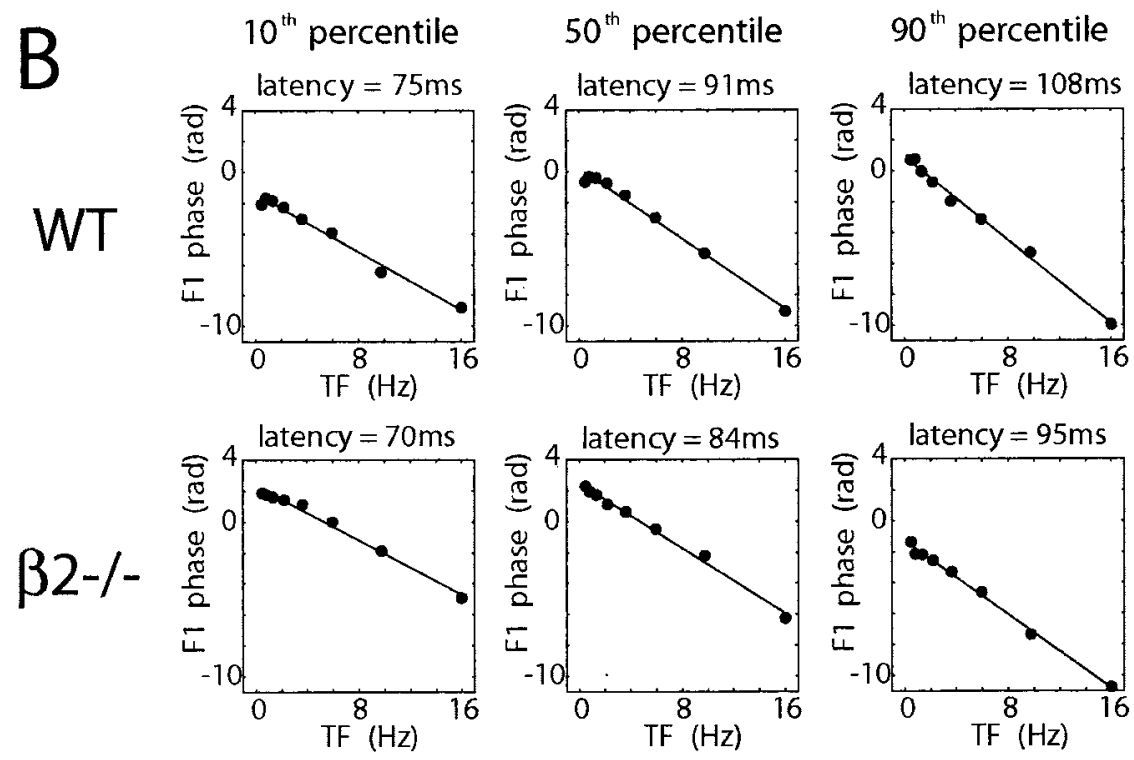

Figure 6. Examples of TF tuning in WT and $\beta 2-/-\mathrm{dLGN}$ cells. Cells were presented with drifting sinusoidal gratings of varying TF (SF, optimal; contrast, 70\%). A, The circles show response amplitudes at the fundamental stimulus harmonic (F1); the solid lines show the best two half-Gaussian fits to these data. Note the logarithmic $x$-axis. Cells were ranked according to their TF peak, and plots for cells at the 25th, 50th, and 75th percentiles are shown. All cells show bandpass TF tuning, with response amplitude decreasing with distance from peak TF. Neurons in $\beta 2-1-$ mice prefer higher TFs than WT cells at similar percentiles. TF tuning characteristics for all example cells: cell 1: peak, $2.9 \mathrm{~Hz}$; high ${ }_{50}, 6.3 \mathrm{~Hz}$; cell 2: peak, $3.8 \mathrm{~Hz}$; high ${ }_{50}, 7.1 \mathrm{~Hz}$; cell 3: peak, $4.4 \mathrm{~Hz}$; high ${ }_{50}, 7.5 \mathrm{~Hz}$; cell 4: peak, $3.4 \mathrm{~Hz}$; high ${ }_{50}, 7.8 \mathrm{~Hz}$; cell 5: peak, $4.8 \mathrm{~Hz}$; high ${ }_{50}, 7.5 \mathrm{~Hz}$; cell 6: peak, $5.8 \mathrm{~Hz}_{\text {; }}$ high $_{50}, 10.5 \mathrm{~Hz}$. $B$, The circles show $F 1$ response phases, whereas the solid lines show the best linear fits to these data. Cells were ranked according to their latency, calculated as the slope of the best-fitting TF phase line (Hawken et al., 1996; Grubb and Thompson, 2003). Plots for cells at the 10th, 50th, and 90th percentiles are shown. Although slopes appear to vary rather little between WT and $\beta 2-1-$ samples, cells in the $\beta 2-/-$ dLGN tend to have shorter latencies than WT neurons at similar percentiles.

though, in showing no significant differences between On-center and Off-center neurons ( $t$ or Mann-Whitney $U$ tests, depending on normality; $p>0.05$ ). In addition, although ANOVA analyses produced significant effects of genotype for all three temporal response measures (latency, peak, $\operatorname{high}_{50} ; p<0.05$ ), no significant effects of RF center type or of genotype $\times$ RF center type were found $(p>0.05)$. WT $-\beta 2-/-$ differences in temporal response properties thus occur equally in On-center and Offcenter dLGN cells (Fig. $7 A_{2}, B_{2}, C_{2}$ ).
Trends toward greater contrast sensitivity in $\beta 2-/-$ neurons

Contrast response characteristics were assessed by presenting drifting sinusoidal gratings of various contrasts at optimal SFs and TFs. Plots of stimulus contrast versus F1 response amplitude were then fitted with a hyperbolic function (Albrecht and Hamilton, 1982; Grubb and Thompson, 2003) (see Materials and Methods) that allowed the calculation of two contrast response parameters: gain, the slope of a tangent to the contrast curve at $20 \%$ of its maximum height, and $c_{50}$, the contrast at which F1 response amplitude reaches 50\% of its maximum (see Materials and Methods).

Contrast response curves were successfully fitted with a hyperbolic function in 35 of the $\beta 2-/-$ cells responding to different contrasts. The WT sample contained 18 curves, representing the subset of the original sample ( $n=58$ ) (Grubb and Thompson, 2003) in which contrast responses were obtained at optimal SFs and TFs. Examples of curves ranked according to contrast gain are shown in Figure 8. $\beta 2-1-$ neurons (Fig. $8 D-F$ ), like cells in the WT dLGN (Fig. $8 A-C$ ), all showed monotonically increasing response amplitude with increasing stimulus contrast. Contrast responses, though, tended to be more sensitive in the $\beta 2-/-\mathrm{dLGN}$. The example cells in Figure 8 show that the contrast gain of $\beta 2-/-$ neurons tended to be higher than that of WT cells at similar sample percentiles. Moreover, the cumulative probability plot in Figure $9 A_{1}$ shows that the $\beta 2-/-$ sample contained a subset of neurons with far higher contrast gain values than any of the cells in the WT sample. Average gain was indeed higher, and the average $c_{50}$ value was lower, in $\beta 2-/-$ versus WT dLGN cells. However, perhaps because of the small size of the WT sample, neither of these trends was significant (median gain: WT, 0.7 spikes $/ \mathrm{sec} / \%$; $\beta 2-/-, 0.9$ spikes/sec/\%; Mann-Whitney $U$ test; $p=0.1)\left(\right.$ Fig. $\left.9 A_{1}\right)\left(c_{50}\right.$, mean \pm SEM: WT, $32 \pm 3 \% ; \beta 2-/-, 26 \pm 2 \% ; t$ test; $p=0.12)\left(\right.$ Fig. $\left.9 B_{1}\right)$.

Because contrast response characteristics differ between On-center and Offcenter cells in the WT dLGN (Grubb and Thompson, 2003), an ANOVA analysis was also applied to jointly examine the effects of genotype and RF center type in these data. Higher gain values in $\beta 2-/-$ cells were reflected in an almost significant effect of genotype $\left(F_{(1,49)}=3.88 ; p=0.055\right)$. Oncenter cells tended to have higher contrast gain, but this effect was not significant $\left(F_{(1,49)}=0.71 ; p=0.4\right)$, and neither was that of the genotype $\times$ RF center-type interaction $\left(F_{(1,49)}=0.37 ; p=0.5\right)$. As in the spontaneous activity data, though, differences between On-center and Off-center cells in $\beta 2-/-$ mice appeared much 
$A_{1}$

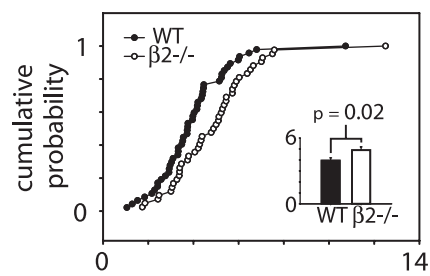

peak $(\mathrm{Hz})$

$\mathrm{B}_{1}$

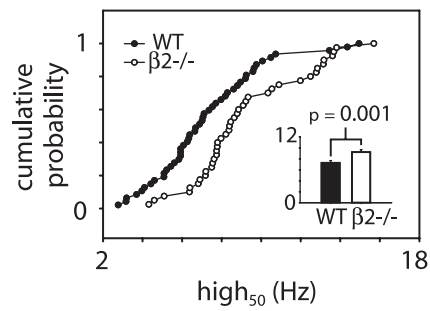

$\mathrm{C}_{1}$

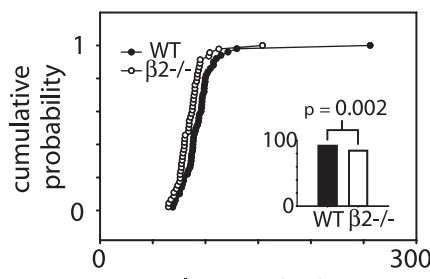

latency (ms)
2

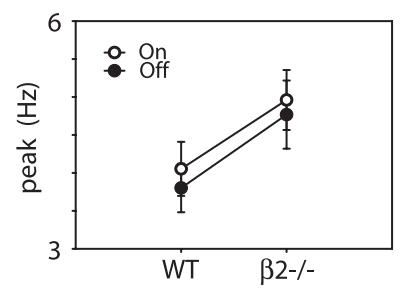

2

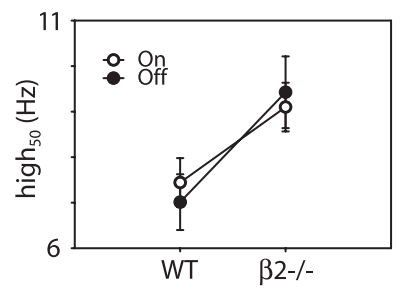

2

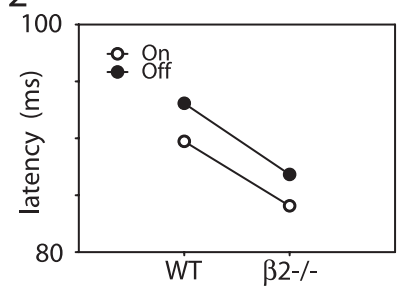

Figure 7. Comparison of TF tuning in the WT and $\beta 2-/-\mathrm{dLGN} . A, \beta 2-/-\mathrm{dLGN}$ cells prefer higher TFs. The cumulative probability plot (1) shows the $\beta 2-1-$ distribution shifted toward higher peak TF values, whereas the bar plot shows that the $\beta 2-1-$ mean peak TF is significantly higher than WT (mean \pm SEM: WT, $3.9 \pm 0.2 \mathrm{~Hz} ; \beta 2-/-, 4.9 \pm 0.3 \mathrm{~Hz} ; t$ test; $p=0.02$ ). The error bars show SEM. Plot 2 shows that peak TF means are higher for both On-center and Off-center cells in the $\beta 2-/-\mathrm{dLGN}$. $B, H_{1 i g h}$ values are higher in the

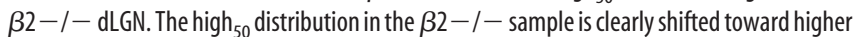
values, and the mean of this sample is significantly greater than that of WT cells (mean \pm SEM: WT, $7.3 \pm 0.4 \mathrm{~Hz} ; \beta 2-/-, 9.2 \pm 0.4 \mathrm{~Hz} ; t$ test; $p=0.001$ ). The error bars show SEM. Plot 2 shows that high ${ }_{50}$ means are higher for both 0 n-center and Off-center cells in the $\beta 2-1-$ $\mathrm{dLGN}$. C, $\beta 2-/-\mathrm{dLGN}$ cells have shorter response latencies than WT dLGN neurons. The distribution of $\beta 2-1-$ latency values is only slightly shifted from that of WT latencies, but the medians of the two samples are significantly different nonetheless (median: WT, $92 \mathrm{msec}$; $\beta 2-/-, 84$ msec; Mann-Whitney $U$ test; $p=0.002$ ). Plot 2 shows that latency medians are lower for both On-center and Off-center cells in the $\beta 2-/-\mathrm{dLGN}$.

less marked than those in WT animals (Fig. $9 A_{2}$ ). This trend was repeated in the $c_{50}$ data (Fig. $9 B_{2}$ ), in which the effect of RF center type was significant $\left(F_{(1,49)}=13.1 ; p=0.001\right)$ but those of genotype $\left(F_{(1,49)}=2.8 ; p=0.1\right)$ and genotype $\times$ RF center type $\left(F_{(1,49)}=1.6 ; p=0.2\right)$ were not. Thus, although most visual processing differences between WT and $\beta 2-/-$ dLGN cells are present in both On-center and Off-center neurons (see above analyses), in those cases in which RF center-type differences were seen in the WT sample (spontaneous activity, contrast gain, $\mathrm{c}_{50}$ ), those differences are markedly reduced in $\beta 2-/-$ mice.

\section{No difference in bursting activity between WT and $\beta 2-/-$ dLGN neurons}

Relay neurons in the dLGN fire spikes in two response modes, burst and tonic, which have been proposed to play distinct roles in the processing of visual information (Sherman, 2001). Switches between burst and tonic firing modes depend on the

status of a time- and voltage-dependent current, $I_{\mathrm{T}}$, which in turn can be affected by a host of modulatory synaptic mechanisms in the thalamus (Sherman and Guillery, 2002). We identified spikes forming part of bursts by analyzing temporal patterns of stimulus-driven firing in WT and $\beta 2-/-$ neurons (see Materials and Methods). The two samples were remarkably similar in terms of the percentage of spikes that form part of bursts (median: WT: $19.8 \%, n=337 ; \beta 2-/-: 20.0 \%, n=213$; Mann-Whitney $U$ test; $p=0.43$ ) (Fig. $10 \mathrm{~A}$ ), the percentage of grating stimulus cycles that evoked at least one burst (median: WT: $25.1 \%, n=337$; $\beta 2-/-: 25.8 \%, n=213$; Mann-Whitney $U$ test; $p=0.41$ ), and burst length (median: WT: 2.5 spikes, $n=332 ; \beta 2-/-: 2.49$ spikes, $n=212$; Mann-Whitney $U$ test; $p=0.29$ ). These similarities in bursting behavior in WT and $\beta 2-/-$ dLGN neurons suggest that differences in visual response properties between the two samples (see above) cannot be attributable to a difference in thalamic firing mode balance between WT and $\beta 2-/-$ neurons. In addition, because the firing mode in thalamic cells depends importantly on the physiological state of the animal (Weyand et al., 2001), the WT- $\beta 2-/-$ similarity in bursting behavior suggests that the general state of the brain and the effects of anesthesia did not differ significantly during recordings from WT and $\beta 2-/-$ dLGN neurons.

Male-only comparisons reveal an identical pattern of results One clear confounding factor when analyzing differences between $\beta 2-/-$ and WT response characteristics is that the WT sample came from mice of either sex, whereas the $\beta 2-/-$ sample was taken from male mice only (see Materials and Methods). Although response properties differ very little between cells recorded in male and female mice (Grubb and Thompson, 2003), this sampling difference may have been responsible for some of the above differences between the two genotypes. For this reason, all the above WT- $\beta 2-/-$ comparisons were also performed using only WT data taken from male mice. In terms of significance, exactly the same pattern of results was obtained, with one exception: TF peak is no longer significantly higher in $\beta 2-/-$ mice if compared with cells from WT males only. However, this is more likely to be an effect of lower sample sizes than of sex differences: no male-female differences in TF tuning were observed in WT mice (Grubb and Thompson, 2003), and the trend toward higher peak TFs in $\beta 2-/-$ cells was still present in the reduced data set (mean \pm SEM: WT: $4.1 \pm 0.4 \mathrm{~Hz}, n=22 ; \beta 2-/-: 4.9 \pm 0.3 \mathrm{~Hz}$, $n=42 ; t$ test; $p=0.15)$.

\section{Discussion}

\section{Normal visual response properties in $\beta 2-/-\mathrm{dLGN}$ cells}

The response characteristics of neurons in the dLGN of anesthetized $\beta 2-/-$ mice are entirely normal in the spatial domain. Linearity of spatial summation, RF sizes, and center-surround interactions do not differ significantly from those in anesthetized WT mice. This normality allows some straightforward conclusions to be drawn concerning spatial processing in the mouse dLGN. First, the spatial properties of mouse dLGN neurons are not influenced in any way by $\beta 2$-nAChRs in the thalamus. Although ACh can alter RF center size (Fjeld et al., 2002) and RF surround strength (Uhlrich et al., 1995) in the adult cat dLGN, if these effects are conserved across mammalian species, they do not require the presence of $\beta 2$-nAChRs.

Second, normal patterns of spontaneous activity in the immature retina are not necessary for the development of normal spatial RF properties in the mouse dLGN. Despite lacking correlated calcium and spike activity in the neonatal retina (Bansal et al., 
$25^{\text {th }}$ percentile
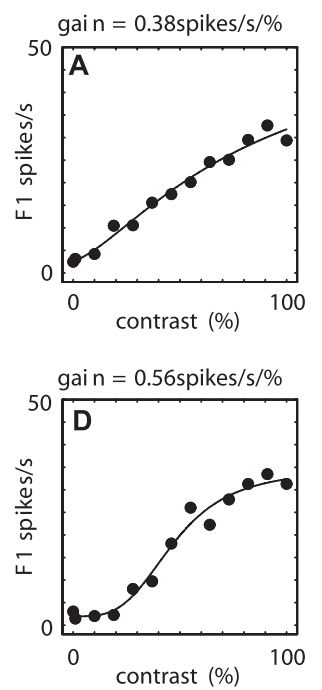

$50^{\text {th }}$ percentile
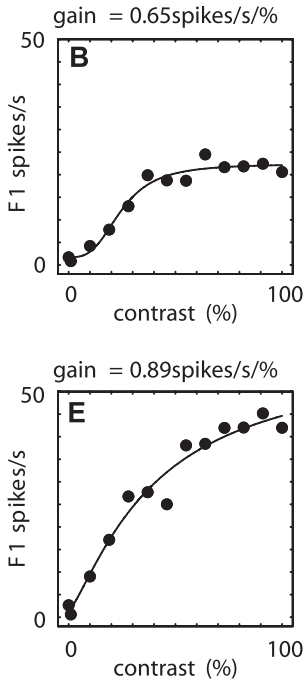

Figure 8. Examples of contrast response characteristics in three WT and three $\beta 2-/-\mathrm{dLGN}$ cells. The circles show F1 response amplitudes to drifting sinusoidal gratings of varying contrast (SF/TF, optimal); the lines show the best-fitting hyperbolic curve to these data (see Materials and Methods). Cells were ranked according to contrast gain (see Results), and plots for cells at the 25 th, 50 th, and 75 th percentiles are shown. Neurons in the $\beta 2-1-\mathrm{dLGN}$ tended to be more responsive to contrast than their WT counterparts: gain values at similar sample percentiles are higher for $\beta 2-/-$ cells. Contrast response data for all example cells: A: gain, 0.38 spikes/sec/\%; $c_{50}, 43.3 \%$; $B$ : gain, 0.65 spikes $/ \mathrm{sec} / \% ; c_{50}, 24.5 \%$; $C$ : gain, 0.97 spikes $/ \mathrm{sec} / \% ; c_{50}$, $35.3 \%$; D: gain, 0.56 spikes $/ \mathrm{sec} / \% ; c_{50}, 45.4 \%$; E: gain, 0.89 spikes $/ \mathrm{sec} / \% ; c_{50}, 27.6 \% ; F$ : gain, 1.14 spikes $/ \mathrm{sec} / \% ; c_{50}, 25.0 \%$.

2000; McLaughlin et al., 2003), $\beta 2-/-$ mice develop normal geniculate spatial response properties. Most spatial response characteristics in dLGN cells are determined by retinal inputs, which are pruned from initially diffuse projections into highly specific, almost 1:1 connections over an extended period of time spanning eye opening (Chen and Regehr, 2000; Tavazoie and Reid, 2000). The present data suggest that this pruning process is unaffected by earlier abnormal patterns of spontaneous retinal activity, even when those abnormal activity patterns are associated with anomalous retinogeniculate projections (Rossi et al., 2001; Muir-Robinson et al., 2002; Grubb et al., 2003). Whether the later glutamatergic waves, which are present in $\beta 2-/-$ mice (Bansal et al., 2000), are involved in this pruning remains to be established.

Third, and perhaps most interesting, the spatial properties of dLGN cells can be normal even when the functional organization of the nucleus is significantly disrupted. The $\beta 2-/-$ dLGN possesses abnormal ocular (Rossi et al., 2001; Muir-Robinson et al., 2002), retinotopic (Grubb et al., 2003), and On-Off (Grubb et al., 2003) organization. Despite these cell rearrangements, spatial processing in the nucleus is entirely normal. Because most spatial response properties are conserved at the retinogeniculate synapse, this implies that the developmental processes responsible for dLGN cell inputs being dominated by a single RGC afferent (Chen and Regehr, 2000; Tavazoie and Reid, 2000) are not dependent on functional organization in the nucleus. This is consistent with the observation that, although ocular organization is disrupted in the $\beta 2-/-\mathrm{dLGN}$, individual neurons in the nucleus are always monocularly driven (Grubb et al., 2003). Geniculate neurons, however, do not inherit all spatial response properties from their retinal inputs: the strength of RF surround mechanisms, for example, is shaped by local thalamic circuitry (Hubel and Wiesel, 1961; Norton et al., 1989; Usrey et al., 1999). Because surround inhibition is entirely normal in the $\beta 2-1-$ dLGN, it appears these intrageniculate processes can also function
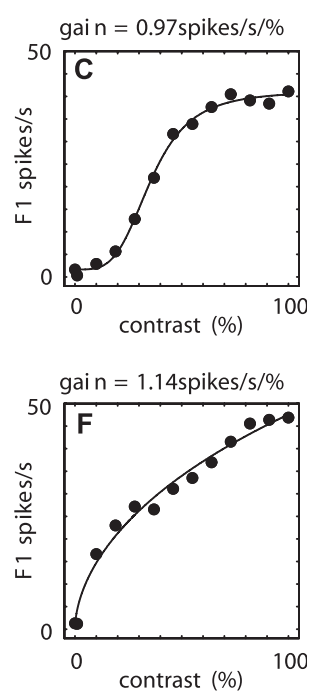

$75^{\text {th }}$ percentile

normally even when the arrangement of cells within the dLGN is altered. Functional organization in the dLGN is thus unnecessary for local spatial processing of visual information. Finally, the normal spatial properties of neurons in the $\beta 2-/-$ dLGN suggest that, should cortical feedback influence geniculate processing of spatial information (Alitto and Usrey, 2003), this feedback is not disrupted by deficient spatial acuity in the $\beta 2-/-$ visual cortex (Rossi et al., 2001).

We should point out that one qualitative spatial difference was found between the $\beta 2-/-$ and WT dLGN. Whereas the WT dLGN sample contained no cells with classic Y-like nonlinearities of spatial summation, one such cell was recorded in the $\beta 2-/-$ nucleus. It is extremely unlikely that this type of cell, found in the dLGN of all mammalian species studied thus far (Grubb and Thompson, 2003), was generated by the $\beta 2-1-$ mutation and does not ever occur in the WT dLGN. It seems far more plausible that both the WT and $\beta 2-/-$ dLGN contain Y-like cells in very small numbers, just like the primate geniculate (Kaplan and Shapley, 1982; Levitt et al., 2001), and that such cells were simply missed in the WT sample.

The other domain in which $\beta 2-1-$ dLGN physiology was strikingly normal was that of the response mode: visually driven bursting behavior in WT and $\beta 2-/-$ geniculate cells was indistinguishable in the anesthetized preparation. ACh can decrease burst firing in the cat dLGN (Lu et al., 1993), but if this effect is conserved across mammals, it does not rely on $\beta 2$-nAChRs. Indeed, because of the long period of depolarization needed to inactivate the calcium channel that underlies bursting activity (Sherman, 2001), it has been suggested that muscarinic AChRs are much better suited than faster-acting $\mathrm{nAChRs}$ to switch firing modes in thalamic neurons (Godwin et al., 1996). However, it should be noted that we have not examined burst firing in the awake behaving preparation, and it is quite possible that $\beta 2$-nAChRs could be involved in modulation of burst firing in this state. Indeed, it could be argued that this also applies to the "normal" spatial properties of the $\beta 2-/-$ cells that we report here. If those were to differ in the awake behaving preparation, they would identify the contribution of $\beta 2$-nAChRbased brainstem modulation to spatial vision.

\section{Abnormal visual response properties in $\beta 2-/-\mathrm{dLGN}$ cells} Cells in the $\beta 2-/-$ dLGN have higher levels of spontaneous activity than WT geniculate neurons. As evidenced by greater RF center strength in the absence of any change in RF center radius, and by a strong trend toward higher contrast gain, $\beta 2-/-$ dLGN neurons are also more visually responsive than cells in the WT nucleus. In addition, cells in $\beta 2-/-$ mice respond with quicker latencies and prefer higher TFs than neurons in WT animals. We have made the assumption that these differences reflect true differences in the geniculate population rather than a difference arising from a change in electrode sampling bias associated with the mutation. Although a change in sampling bias is a possibility, we feel that this is less likely given the similarity of the spatial properties of WT and mutant populations.

Because the $\beta 2-/-$ mutation renders $\beta 2$-nAChRs nonfunc- 
A

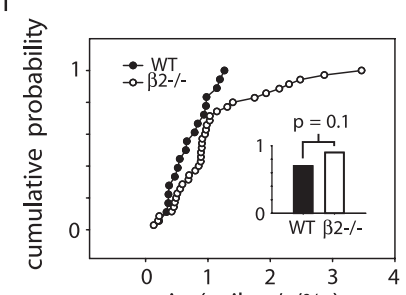

$\mathrm{B}_{1}$

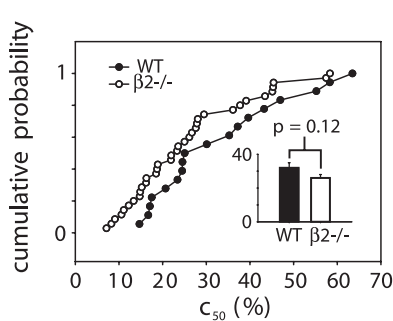

2

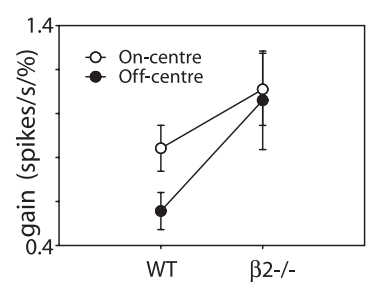

2

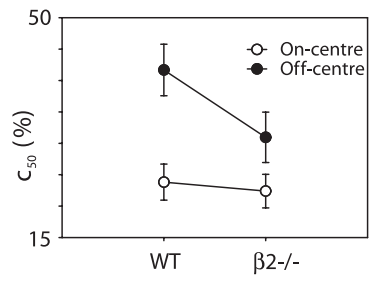

Figure 9. Comparison of contrast response characteristics in WT and $\beta 2-/-\mathrm{dLGN} . A, A$ trend toward higher contrast gain in $\beta 2-/-\mathrm{dLGN}$ cells. The cumulative probability plot ( 1 ) indicates that cells in the $\beta 2-/-$ sample tend to have higher contrast gain than their WT counterparts. The bar plot (inset), however, shows that the medians of the two samples are not significantly different (median: WT, 0.7 spikes/sec/\%; $\beta 2-/-, 0.9$ spikes/sec/\%; MannWhitney $U$ test; $p=0.1$ ). Plot 2 shows mean \pm SEM for 0 n-center and Off-center cells in both samples (mean \pm SEM is shown here because a parametric ANOVA test was used to analyze these data). $0 \mathrm{n}$-center and Off-center cells in the $\beta 2-/-\mathrm{dLGN}$ have higher mean gain values than both cell types in the WT dLGN, but the effect of genotype is not quite significant on a two-way ANOVA $\left(F_{(1,49)}=3.88 ; p=0.055\right)$. Although On-center cells have significantly higher gain than Off-center cells in the WT dLGN (Grubb and Thompson, 2003), this is not the case in $\beta 2-/-$ mice. Neither the effect of RF center type $\left(F_{(1,49)}=0.71 ; p=0.4\right)$ nor the center type $\times$ genotype interaction $\left(F_{(1,49)}=0.37 ; p=0.5\right)$ are significant. Mean \pm SEM values: WT On-center, $0.84 \pm 0.1$ spikes $/ \mathrm{sec} / \%$; WT Off-center, $0.56 \pm 0.08 \mathrm{spikes} / \mathrm{sec} / \% ; \beta 2-/-$ On-center, $1.11 \pm 0.16 \mathrm{spikes} / \mathrm{sec} / \% ; \beta 2-/-0$ off-center, $1.06 \pm 0.22 \mathrm{spikes} / \mathrm{sec} / \%$. The error bars show SEM. $B, A$ weaker trend toward lower $c_{50}$ values in the $\beta 2-/-\mathrm{dLGN}$. Plot 2 shows that $\beta 2-/-$ neurons generally have slightly lower $c_{50}$ values than cells in the WT dLGN. The difference between the means of the two samples, however, is not significantly different (mean \pm SEM:WT, $32 \pm 3 \% ; \beta 2-1-, 26 \pm 2 \% ; t$ test; $p=0.12$ ). Plot 2 shows mean \pm SEM for On-center and Off-center cells in both samples. On-center $c_{50}$ means differ little between genotypes, but 0 ff-center means are much lower in $\beta 2-/-\mathrm{dLGN}$ cells. The effect of genotype is not significant, however $\left(F_{(1,49)}=2.8 ; p=0.1\right)$. The effect of RF center type is significant, with 0 -center $c_{50}$ values significantly lower across both genotype groups $\left(F_{(1,49)}=13.1 ; p=\right.$ $0.001)$. The genotype $\times$ center-type interaction is not significant $\left(F_{(1,49)}=1.6 ; p=0.2\right)$. Mean \pm SEM values: WT 0n-center, $24 \pm 3 \%$; WT Off-center, $42 \pm 4 \% ; \beta 2-/-0$-center, $22 \pm 3 \% ; \beta 2-/-0 f f-c e n t e r, 31 \pm 4 \%$. The error bars show SEM.

tional throughout the brain and throughout development, it is important to consider precisely where and when these abnormalities arise. Abnormal visual response properties in $\beta 2-/-\mathrm{dLGN}$ cells could be the result of altered thalamic processing but could also be inherited directly from RGCs. Descriptions of visual processing capabilities in the $\beta 2-/-$ retina are needed to resolve this issue. We encountered no S-potentials in our recordings and so were unable to directly compare retinal and geniculate tuning. Temporally, higher activity levels and enhanced TF processing could arise because of altered developmental processes in the $\beta 2-/-$ visual system, or because of a lack of $\beta 2$-nAChRs in the adult brain. Because ACh increases both spontaneous and visually driven activity in the adult dLGN (Sillito et al., 1983; Fjeld et al., 2002 ), a lack of $\beta 2$-nAChRs in the adult nucleus might be expected to decrease firing rates, the opposite effect to that observed. Does this mean that increased firing rates in the $\beta 2-/-$ dLGN must have a developmental cause? Not necessarily. Although ACh increases activity levels in the adult dLGN, it is not at all clear that it does so through $\beta 2$-nAChRs. Indeed, transmission through nAChRs not

A

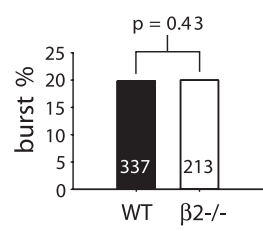

B
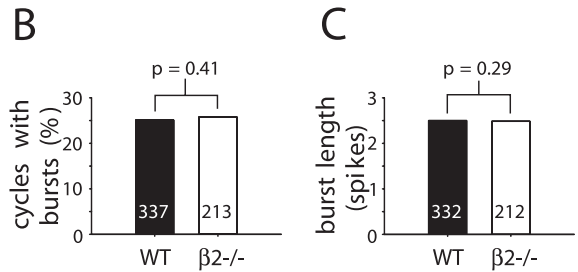

Figure 10. No difference in bursting activity between WT and $\beta 2-/-\mathrm{dLGN}$ cells. Plots show median values for WT and $\beta 2-/-\mathrm{dLGN}$ cells across all tuning curve experiments. The numbers within the bars show the numbers for each sample. WT and $\beta 2-1-\mathrm{dLGN}$ neurons do not differ with respect to the percentage of spikes that form part of bursts (burst \%; median: WT, 19.8\%; $\beta 2-I-, 20.0 \%$; Mann-Whitney $U$ test; $p=0.43$; $A$ ), the percentage of presented stimulus cycles that evoked at least one burst (cycles with bursts; median: WT, 25.1\%; $\beta 2-/-, 25.8 \%$; Mann-Whitney $U$ test; $p=0.41 ; B$ ) or the length of each burst (burst length; median: WT, 2.5 spikes; $\beta 2-/-, 2.49$ spikes; Mann-Whitney $U$ test; $p=0.29 ;($ ).

only depolarizes relay neurons in the adult dLGN, it also depolarizes interneurons that provide relay cells with inhibitory input (Lena and Changeux, 1997; Zhu and Uhlrich, 1997). Local circuitry in the adult dLGN might therefore produce increased activity levels when $\beta 2$ nAChRs are nonfunctional. Indeed, the effect could even be cortical in origin, given the complexity of cortico-thalamic feedback to dLGN and reticular nucleus.

To locate the precise spatial and temporal effects of the $\beta 2-/-$ mutation on response properties in the adult dLGN will require some careful future experiments. One approach could involve studying the response properties of adult WT dLGN neurons during local blockade of $\beta 2-n A C h R s$. The availability of conditional mutant mice that lack $\beta 2$-nAChRs only in the retina, only in the thalamus, or only at particular stages in development (cf. Lewandoski 2001) would also be extremely helpful in determining the underlying causes of the $\beta 2-/-$ abnormalities reported here.

\section{Some implications}

Despite raising interpretational problems of their own, the increased activity and enhanced temporal properties of $\beta 2-1-$ dLGN cells might prove useful in interpreting future data concerning the $\beta 2-/-$ visual system. Joined with the normal spatial processing features discussed above, these observations lead to the basic conclusion that visual processing in the $\beta 2-/-\mathrm{dLGN}$ is no worse than normal. This is an extremely useful piece of information to have when interpreting abnormalities in visual function in the $\beta 2-/-$ cortex. Evoked potential recordings have already shown that spatial acuity is reduced in the $\beta 2-/-$ cortex but not in the $\beta 2-/-$ retina (Rossi et al., 2001). The spatial data presented here, especially the almost indistinguishable distributions of SF cutoff values in WT and $\beta 2-/-$ dLGN cells, make it extremely likely that this loss of spatial acuity occurs not in the thalamus but in cortex. Should future studies uncover other visual processing deficits in $\beta 2-1-$ cortex, the present data can be used to argue that such deficits are also attributable to specifically cortical abnormalities.

On a different note, having discussed whether abnormal functional organization could be responsible for the differences in single-cell response properties between $\beta 2-/-$ and WT dLGN cells, the inverse possibility should also be presented. Could increased activity levels and enhanced temporal properties in $\beta 2-/-$ dLGN cells disrupt the functional organization of the nucleus? In particular, could these response abnormalities be responsible for the supernormal formation of On-center and Offcenter domains in the $\beta 2-/-\mathrm{dLGN}$ (Grubb et al., 2003)? This is 
certainly a possibility. Increased visual responses could enhance differences in activity between On-center and Off-center cells, whereas shorter latencies and higher TF responsivity in the $\beta 2-/-$ dLGN might make for better detection of synchronous inputs onto thalamocortical relay cells. Competition for inputs under Hebbian rules (Lee et al., 2002) might therefore be enhanced, leading to organizational features not seen in WT animals. However, it should be noted that such possible "enhancement" mechanisms do not prevent the loss of fine retinotopy in the $\beta 2-/-$ dLGN (Grubb et al., 2003). To provide solid data rather than conjecture on these issues, the development of singleunit response properties and functional organization in the $\beta 2-/-$ and WT mouse dLGN needs to be followed as it happens.

\section{References}

Albrecht DG, Hamilton DB (1982) Striate cortex of monkey and cat: contrast response function. J Neurophysiol 48:217-237.

Alitto HJ, Usrey WM (2003) Corticothalamic feedback and sensory processing. Curr Opin Neurobiol 13:440-445.

Bansal A, Singer JH, Hwang BJ, Xu W, Beaudet A, Feller MB (2000) Mice lacking specific nicotinic acetylcholine receptor subunits exhibit dramatically altered spontaneous activity patterns and reveal a limited role for retinal waves in forming $\mathrm{ON}$ and OFF circuits in the inner retina. J Neurosci 20:7672-7681.

Chen C, Regehr WG (2000) Developmental remodeling of the retinogeniculate synapse. Neuron 28:955-966.

Enroth-Cugell C, Robson JG (1966) The contrast sensitivity of retinal ganglion cells of the cat. J Physiol (Lond) 187:517-552.

Fjeld IT, Ruksenas O, Heggelund P (2002) Brainstem modulation of visual response properties of single cells in the dorsal lateral geniculate nucleus of cat. J Physiol (Lond) 543:541-554.

Fraunfelder FT, Burns RP (1970) Acute reversible lens opacity: caused by drugs, cold, anoxia, asphyxia, stress, death and dehydration. Exp Eye Res 10:19-30.

Godwin DW, Vaughan JW, Sherman SM (1996) Metabotropic glutamate receptors switch visual response mode of lateral geniculate nucleus cells from burst to tonic. J Neurophysiol 76:1800-1816.

Grubb MS, Thompson ID (2003) Quantitative characterization of visual response properties in the mouse dorsal lateral geniculate nucleus. J Neurophysiol 90:3594-3607.

Grubb MS, Rossi FM, Changeux JP, Thompson ID (2003) Abnormal functional organization in the dorsal lateral geniculate nucleus of mice lacking the $\beta 2$ subunit of the nicotinic acetylcholine receptor. Neuron 40:1161-1172.

Hawken MJ, Shapley RM, Grosof DH (1996) Temporal-frequency selectivity in monkey visual cortex. Vis Neurosci 13:477-492.

Hochstein S, Shapley RM (1976) Quantitative analysis of retinal ganglion cell classifications. J Physiol (Lond) 262:237-264.

Hubel DH, Wiesel TN (1961) Integrative action in the cat's lateral geniculate body. J Physiol (Lond) 155:385-398.

Jahnsen H, Llinas R (1984) Electrophysiological properties of guinea-pig thalamic neurones: an in vitro study. J Physiol (Lond) 349:205-226.

Kaplan E, Shapley RM (1982) X and Y cells in the lateral geniculate nucleus of macaque monkeys. J Physiol (Lond) 330:125-143.

Kim D, Song I, Keum S, Lee T, Jeong MJ, Kim SS, McEnery MW, Shin HS (2001) Lack of the burst firing of thalamocortical relay neurons and resistance to absence seizures in mice lacking alpha(1G) T-type $\mathrm{Ca}(2+)$ channels. Neuron 31:35-45.

Lee CW, Eglen SJ, Wong RO (2002) Segregation of ON and OFF retinogeniculate connectivity directed by patterned spontaneous activity. J Neurophysiol 88:2311-2321.

Lena C, Changeux JP (1997) Role of $\mathrm{Ca}^{2+}$ ions in nicotinic facilitation of GABA release in mouse thalamus. J Neurosci 17:576-585.

Lennie P, Perry VH (1981) Spatial contrast sensitivity of cells in the lateral geniculate nucleus of the rat. J Physiol (Lond) 315:69-79.

Levitt JB, Schumer RA, Sherman SM, Spear PD, Movshon JA (2001) Visual response properties of neurons in the LGN of normally reared and visually deprived macaque monkeys. J Neurophysiol 85:2111-2129.
Lewandoski M (2001) Conditional control of gene expression in the mouse. Nat Rev Genet 2:743-755.

Lu SM, Guido W, Sherman SM (1992) Effects of membrane voltage on receptive field properties of lateral geniculate neurons in the cat: contributions of the low-threshold $\mathrm{Ca}^{2+}$ conductance. J Neurophysiol 68:2185-2198.

Lu SM, Guido W, Sherman SM (1993) The brain-stem parabrachial region controls mode of response to visual stimulation of neurons in the cat's lateral geniculate nucleus. Vis Neurosci 10:631-642.

McCarley RW, Benoit O, Barrionuevo G (1983) Lateral geniculate nucleus unitary discharge in sleep and waking: state- and rate-specific aspects. J Neurophysiol 50:798-818.

McCormick DA, Feeser HR (1990) Functional implications of burst firing and single spike activity in lateral geniculate relay neurons. Neuroscience 39:103-113.

McLaughlin T, Torborg CL, Feller MB, O'Leary DD (2003) Retinotopic map refinement requires spontaneous retinal waves during a brief critical period of development. Neuron 40:1147-1160.

Muir-Robinson G, Hwang BJ, Feller MB (2002) Retinogeniculate axons undergo eye-specific segregation in the absence of eye-specific layers. J Neurosci 22:5259-5264.

Norton TT, Holdefer RN, Godwin DW (1989) Effects of bicuculline on receptive field center sensitivity of relay cells in lateral geniculate nucleus. Brain Res 488:348-352.

Picciotto MR, Zoli M, Lena C, Bessis A, Lallemand Y, LeNovere N, Vincent P, Pich EM, Brulet P, Changeux JP (1995) Abnormal avoidance learning in mice lacking functional high-affinity nicotine receptor in the brain. Nature 374:65-67.

Radhakrishnan V, Tsoukatos J, Davis KD, Tasker RR, Lozano AM, Dostrovsky JO (1999) A comparison of the burst activity of lateral thalamic neurons in chronic pain and non-pain patients. Pain 80:567-575.

Ramcharan EJ, Cox CL, Zhan XJ, Sherman SM, Gnadt JW (2000) Cellular mechanisms underlying activity patterns in the monkey thalamus during visual behavior. J Neurophysiol 84:1982-1987.

Reinagel P, Godwin D, Sherman SM, Koch C (1999) Encoding of visual information by LGN bursts. J Neurophysiol 81:2558-2569.

Rodieck RW (1965) Quantitative analysis of cat retinal ganglion cell response to visual stimuli. Vision Res 5:583-601.

Rossi FM, Pizzorusso T, Porciatti V, Marubio LM, Maffei L, Changeux JP (2001) Requirement of the nicotinic acetylcholine receptor beta 2 subunit for the anatomical and functional development of the visual system. Proc Natl Acad Sci USA 98:6453-6458.

Sherman SM (2001) Tonic and burst firing: dual modes of thalamocortical relay. Trends Neurosci 24:122-126.

Sherman SM, Guillery RW (2002) The role of the thalamus in the flow of information to the cortex. Philos Trans R Soc Lond B Biol Sci 357:1695-1708.

Sillito AM, Kemp JA, Berardi N (1983) The cholinergic influence on the function of the cat dorsal lateral geniculate nucleus (dLGN). Brain Res 280:299-307.

So YT, Shapley R (1981) Spatial tuning of cells in and around lateral geniculate nucleus of the cat: $\mathrm{X}$ and $\mathrm{Y}$ relay cells and perigeniculate interneurons. J Neurophysiol 45:107-120.

Tavazoie SF, Reid RC (2000) Diverse receptive fields in the lateral geniculate nucleus during thalamocortical development. Nat Neurosci 3:608-616.

Uhlrich DJ, Tamamaki N, Murphy PC, Sherman SM (1995) Effects of brain stem parabrachial activation on receptive field properties of cells in the cat's lateral geniculate nucleus. J Neurophysiol 73:2428-2447.

Usrey WM, Reppas JB, Reid RC (1999) Specificity and strength of retinogeniculate connections. J Neurophysiol 82:3527-3540.

Weyand TG, Boudreaux M, Guido W (2001) Burst and tonic response modes in thalamic neurons during sleep and wakefulness. J Neurophysiol 85:1107-1118.

Zhan XJ, Cox CL, Rinzel J, Sherman SM (1999) Current clamp and modeling studies of low-threshold calcium spikes in cells of the cat's lateral geniculate nucleus. J Neurophysiol 81:2360-2373.

Zhu JJ, Uhlrich DJ (1997) Nicotinic receptor-mediated responses in relay cells and interneurons in the rat lateral geniculate nucleus. Neuroscience 80:191-202. 